\title{
Educación por y para los derechos humanos: el caso del control de convencionalidad (*)
}

\section{POR LAUTARO EZEQUIEL PITTIER $(* *)$ Y RICARDO GERMÁN RINCÓN(***)}

\author{
Sumario: I. Introducción.- II. El conocimiento y desconocimiento \\ del control de Convencionalidad.- III. A modo de conclusión.- IV. \\ Bibliografía.
}

Resumen: la educación por y para los derechos humanos se ha trasformado en una necesidad imperiosa para la plena vigencia de los mismos. Se trata de un punto de partida para lograr cambios significativos en este asunto. El presente trabajo se concentra en identificar y visibilizar el grado de conocimiento de una herramienta como la del control de convencionalidad en funcionarios calificados del Estado Argentino obligados a ejercer el control de convencionalidad.

Palabras claves: educación - derechos humanos - convencionalidad conocimiento - formación

$(*)$ El presente trabajo es un avance de investigación del Proyecto Lomas CYT de la Facultad de Derecho de la Universidad Nacional de Lomas de Zamora (UNLZ). El Control de Convencionalidad en la Argentina y su relación con el principio internacional de progresividad de los Derechos Humanos - Análisis del desarrollo del control de convencionalidad local e internacional - Expediente 260.719/19 Código LOMASCYT IV FD 77. Dirigido por los Dres. Ricardo German Rincón y Lautaro Ezequiel Pittier.

(**) Abogado. Prof. Universitario en Ciencias Jurídicas. Dir. de Asuntos Jurídicos, Facultad de Derecho, Universidad Nacional de Lomas de Zamora (UNLZ). Prof. adjunto de Derechos Humanos y de Derecho Constitucional Argentino, Facultad de Derecho, Universidad Nacional de Lomas de Zamora. Prof. Asociado en la ECAE. Prof. de la Escuela de Abogacía, Asesoría de Gobierno de la Provincia de Buenos Aires. Dir. del Instituto de Derechos Humanos, Colegio de Abogados de Lomas de Zamora (CALZ). Codirector investigación Lomas CyT "El Control de Convencionalidad en la Argentina y su relación con el principio internacional de progresividad de los Derechos Humanos.

(***) Prof. de Historia. Abogado. Esp. en Gestión y Políticas Universitarias en el Mercosur. Decano de la Facultad de Derecho y Ciencias Sociales de la Universidad del Este (UDE). Prof. titular de Historia Constitucional, Universidad del Este (UDE). Prof. adjunto ordinario de Derecho Político, Universidad Nacional de Lomas de Zamora (UNLZ). Dir. investigación Lomas CyT "El Control de Convencionalidad en la Argentina y su relación con el principio internacional de progresividad de los Derechos Humanos". 


\section{Education by and for human rights: the case of conventionality control}

Abstract: eeducation for human rights has become an imperative need for their full validity. It is a starting point to achieve significant changes in this matter. This work focuses on identifying and making visible the degree of knowledge of a tool such as conventionality control in qualified officials of the Argentine State who are obliged to exercise conventionality control.

Keywords: education - human Rights - conventionality - knowledge - training

\section{Introducción}

La educación por y para los derechos humanos requiere ser entendida como la firme apuesta programática de un Estado para el crecimiento sostenido que requiere cualquier nación para alcanzar el más alto grado de satisfacción de los derechos de sus ciudadanos.

En este sentido, señala Pittier (2011, p. 115) que "la mejor receta para superar los problemas nacionales de largo aliento se encuentra en el terreno de la educación. Solo una firme apuesta por el mejoramiento de la calidad de la enseñanza abrirá la puerta hacia la reconstrucción axiológica que tanto necesitamos".

De conformidad con la afirmación precedente, la educación no debe ser considerada tan solo como un derecho individual subjetivo para todos, sino también social y difuso pues tiene por objeto el fortalecimiento de los derechos humanos. Este derecho subjetivo se traduce también como un deber objetivo del estado, por lo menos respecto de la República Argentina y a partir de una lectura meditada del artículo 75 inc. 19 de nuestra Constitución Nacional (CN), dado que ella posibilita a los seres humanos ser autónomos, tener mejor calidad de vida, tomar correctas decisiones, y ser solidarios (entre otras tantas posibilidades de manifestación).

En este orden de ideas, la enseñanza de los derechos humanos es una responsabilidad de todo el sistema educativo, considerado como conjunto, más allá de sus divisiones en jurisdicciones, niveles, modalidades, ámbitos y gestiones.

Profundizando en esta línea, la formación de las/os abogadas/os que cumplen los roles de jueces y funcionarios encargados de aplicar el control de convencionalidad se produce fundamentalmente en el sistema universitario y a partir de sus carreras de base. En el caso particular del poder judicial, los jueces no están obligados legalmente (1) a actualizarse, a educarse en derechos humanos ni a ac-

(1) Basta confrontar esta afirmación con el artículo 110 de nuestra Carta Magna y la profusa doctrina vertida en su análisis. 
tualizar conocimientos en materia de Estándares Internacionales. Consideremos simplemente cuántos de ellos juraron como jueces, fiscales o defensores oficiales antes de 1994; o antes de crearse el control de convencionalidad; o antes de que algunos instrumentos internacionales sobre derechos humanos se jerarquizaran constitucionalmente (2) o se ratificaran por nuestro país.

A pesar de que el corpus de derechos humanos reconocidos por nuestro país se ha expandido, los funcionarios judiciales y del ministerio público amparados en su inamovilidad no tienen obligación de acudir a capacitaciones periódicas sobre el tema (3).

\section{El conocimiento y desconocimiento del control de convencionalidad}

El término "control de convencionalidad" fue mencionado por primera vez en el caso "Myrna Mack Chang" en el año 2003 (4), a través del voto razonado del juez de nacionalidad mexicana Sergio García Ramírez. Esto no quiere decir que solo a partir del citado asunto la Corte Interamericana de Derechos Humanos haya ejercido la potestad que el término implica. Desde sus orígenes el cuerpo ha hecho una comparación entre los esquemas jurídicos en tensión de los casos sometidos a su análisis destacando la prioridad de la regla supranacional/convencional por sobre el derecho interno de cada Estado.

El control de convencionalidad consiste en que los jueces de los estados adherentes deben establecer, en los casos concretos sometidos a su jurisdicción, si un acto o una normativa de derecho interno resultan incompatibles con la Convención Americana de Derechos Humanos (en adelante CADH) y los estándares interpretativos que la Corte Interamericana de Derechos Humanos (en adelante Corte IDH) ha acuñado a su respecto. Este deber se yergue sobre la obligación de tutela de los derechos fundamentales asumida por los Estados signatarios de la $\mathrm{CADH}$. El control persigue como propósito la reforma o la abrogación de la práctica o norma incompatible con la CAD, según corresponda, en orden a la protección de los derechos humanos (5).

(2) Por aplicación del mecanismo del artículo 75 inc. 22 CN.

(3) Es un viejo paradigma que tenía relación con al antiguo formato de educación universitaria en el cual se suponía que un profesional recibí en los años de formación todo el conocimiento que iba a necesitar para desarrollar su profesión. Esta situación hoy genera una tensión al interior del sistema jurisdiccional.

(4) Corte IDH, "Myrna Mack Chang vs. Guatemala", del 25-11-03, Serie C, № 101, del voto razonado del juez Sergio García Ramírez.

(5) Para mayor abundamiento, ver Pittier (2020, p. 173). 
El control de convencionalidad, mentado por Sergio García Ramírez (6), no implica ninguna obligación adicional para los estados. No se trata más que de cumplir con las obligaciones internacionales contenidas en la CADH y con la interpretación que de las mismas haga la Corte Interamericana de Derechos Humanos. En efecto, el control de convencionalidad es la interpretación del derecho interno de los estados con base en el texto de la $\mathrm{CADH}(7)$.

Así, el control de convencionalidad debe ser considerado un mecanismo que se ejerce para verificar que una ley, reglamento o acto de las autoridades del Estado, se ajustan a las normas, los principios y obligaciones de la Convención Americana de Derechos Humanos; principalmente, en la que funda la competencia contenciosa de la Corte IDH.

Podemos precisar algunas cuestiones sobre las que no existe discusión:

- Equivale, en su ámbito, al control de constitucionalidad que ejercen los tribunales constitucionales (o todos los tribunales en control difuso (8)).

- Cualquier autoridad interna está obligada a aplicar las disposiciones de orden internacional y a ejercer el control de convencionalidad ex officio entre las normas internas y la Convención Americana.

- El control de convencionalidad se debe extender a las demás convenciones interamericanas de derechos humanos que fundamenten la competencia de la Corte Interamericana y que establezcan obligaciones para el Estado.

- Los Estados deben cumplir con la jurisprudencia de la Corte Interamericana de Derechos Humanos.

- Que la evolución conceptual del control de convencionalidad determinó que deben ejercerlo: 1) Poder Judicial (caso "Almonacid Arellano y otros $v$ s. Chile", del año 2006); 2) Órganos del Poder Judicial y control de oficio (caso

(6) La terminología utilizada, esto es, control de convencionalidad, fue mencionada por primera vez en el caso Myrna Mack Chang, en el año 2003, a través del voto razonado del Juez Sergio García Ramírez en "Myrna Mack Chang vs. Guatemala", sentencia del 25 de noviembre de 2003, Serie C No 101 del voto razonado del juez Sergio García Ramírez, pero la Corte IDH recién lo conceptualizó en 2006 con "Almoracid Arellano c/ Chile" y la Corte Suprema de Justicia de la Nación lo utilizó en el fallo Mazzeo en 2007.

(7) El concepto de control de convencionalidad puede ser empleado en relación a cualquier tratado de DDHH suscripto por un estado cuando este acepta la competencia del órgano de control creado por el mismo tratado. Es una práctica usual establecer una autoridad que interprete el tratado y que resuelva las cuestiones que los estados le sometan además de solicitar los informes periódicos que los estados se obligan a enviar para relevar el avance de la aplicación de los mismos.

(8) Este es el sistema que corresponde a nuestro país. 
“Trabajadores Cesados del Congreso vs. Perú”, del año 2008); 3) Jueces y órganos vinculados con la administración de justicia en todos los niveles (caso “Cabrera García y Montiel Flores vs. México", del año 2008); y 4) Cualquier autoridad pública y no solo el Poder Judicial (caso "Gelman $v s$. Uruguay", del año 2011) (9).

- Dentro de este esquema los jueces y órganos nacionales deben salvaguardar no solo los derechos fundamentales previstos en el ámbito interno, sino también el conjunto de valores, principios y derechos humanos que el Estado ha reconocido en los instrumentos internacionales y cuyo compromiso internacional asumió.

La Corte Interamericana continuó desarrollando y ampliando la conceptualización del control de convencionalidad a través de sus sentencias.

Posteriormente al caso "Almonacid Arellano", en el caso “Trabajadores Cesados del Congreso", la Corte IDH retomó su criterio de control de convencionalidad y además enfatizó la necesidad de que la CADH y los demás tratados internacionales de derechos humanos tengan un efecto útil, procediendo consecuencialmente a determinar:

(...) los órganos del Poder Judicial deben ejercer no sólo un control de constitucionalidad, sino también 'de convencionalidad' ex officio entre las normas internas y la Convención Americana, evidentemente en el marco de sus respectivas competencias y de las regulaciones procesales correspondientes. Esta función no debe quedar limitada exclusivamente por las manifestaciones o actos de los accionantes en cada caso concreto, aunque tampoco implica que ese control deba ejercerse siempre, sin considerar otros presupuestos formales y materiales de admisibilidad y procedencia de ese tipo de acciones (10).

Así, este segundo precedente pone en cabeza de las autoridades judiciales la garantía del efecto útil de los tratados internacionales, relacionando de manera inescindible el control de constitucionalidad con el control de convencionalidad(11).

Señala la Corte que, si bien el control de convencionalidad no es irrestricto, pues está sujeto a presupuestos formales y materiales, sí debe ejercerse sin hacerlo

(9) Se desprende de esta progresividad cronológica como la CIDH ha ido precisando los alcances de los sujetos obligados a ejercer el control.

(10) Párrafo 128, Corte IDH, 2006, serie C No. 158.

(11) En idéntico sentido, ver Corte IDH, caso "Boyce y otros vs. Barbados", sentencia de 20 de noviembre de 2007, Serie C No. 169, párr. 78. 
depender de las manifestaciones o actos de las personas accionantes en cada caso concreto (naturaleza oficiosa).

En el caso Gelman $v s$. Uruguay (12) se produce un avance que plantea un control más allá de los jueces, al señalar que "cuando un Estado es Parte de un tratado internacional como la Convención Americana, todos sus órganos, incluidos sus jueces, están sometidos a aquel" (13), lo cual les obliga a velar por que los efectos de las disposiciones de la Convención no se vean mermados por la aplicación de normas contrarias a su objeto y fin, por lo que los jueces y órganos vinculados a la administración de justicia en todos los niveles están en la obligación de ejercer ex officio un "control de convencionalidad" entre las normas internas y la Convención Americana, evidentemente en el marco de sus respectivas competencias y de las regulaciones procesales correspondientes y en esta tarea, deben tener en cuenta no solamente el tratado, sino también la interpretación que del mismo ha hecho la Corte Interamericana, intérprete última de la Convención Americana.

Asimismo, esta Corte considera pertinente recordar, sin perjuicio de lo ordenado, que en el ámbito de su competencia "todas las autoridades y órganos de un Estado Parte en la Convención tienen la obligación de ejercer un 'control de convencionalidad" (14).

En el sentido expresado la Corte IDH ha precisado también que el control de convencionalidad puede implicar la expulsión de normas contrarias a la $\mathrm{CADH}$, o bien, su interpretación conforme a la misma. En este resquicio es por donde se cuela el denominado "margen de apreciación nacional de los tratados internacionales" sobre el que nos referimos en un trabajo anterior.

(12) "Gelman vs. Uruguay". Fondo y Reparaciones. Sentencia de 24 de febrero de 2011.

(13) La Corte en el caso Gelman señaló que "La sola existencia de un régimen democrático no garantiza, per se, el permanente respeto del Derecho Internacional, incluyendo al Derecho Internacional de los Derechos Humanos, lo cual ha sido así considerado incluso por la propia Carta Democrática Interamericana. La legitimación democrática de determinados hechos o actos en una sociedad está limitada por las normas y obligaciones internacionales de protección de los derechos humanos reconocidos en tratados como la Convención Americana, de modo que la existencia de un verdadero régimen democrático está determinada por sus características tanto formales como sustanciales, por lo que, particularmente en casos de graves violaciones a las normas del Derecho Internacional de los Derechos, la protección de los derechos humanos constituye un límite infranqueable a la regla de mayorías, es decir, a la esfera de lo 'susceptible de ser decidido' por parte de las mayorías en instancias democráticas, en las cuales también debe primar un 'control de convencionalidad' (...), que es función y tarea de cualquier autoridad pública y no sólo del Poder Judicial” (el destacado es propio de los autores).

(14) Cfr. "Caso Masacre de Santo Domingo vs. Colombia". Excepciones Preliminares, Fondo y Reparaciones. Sentencia de 30 de noviembre de 2012. Serie C No. 259, párr. 142, y Caso "Norín Catrimán y otros (Dirigentes, miembros y activista del Pueblo Mapuche) vs. Chile”, párr. 436. 
EDUCACIÓN POR Y PARA LOS DERECHOS HUMANOS: EL CASO DEL CONTROL DE CONVENCIONALIDAD - LAUTARo EZEQUiel PitTIER y RiCARDo GERMán Rincón (PP. 367-384)

A su vez, tanto en el Caso "Almonacid Arellano y otros vs. Chile" (15) como en el Caso "Mendoza y otros vs. Argentina" (16) la Corte IDH dejó establecido que la inconvencionalidad trae como consecuencia la inaplicabilidad de una o varias normas locales en el caso concreto.

Recordemos que en Caso Almonacid Arellano y otros vs. Chile la Corte dijo:

El Estado, desde que ratificó la Convención Americana el 21 de agosto de 1990, ha mantenido vigente el Decreto Ley No. 2.191 por 16 años, en inobservancia de las obligaciones consagradas en aquella. Que tal Decreto Ley no esté siendo aplicado por el Poder Judicial chileno en varios casos a partir de 1998, si bien es un adelanto significativo y la Corte lo valora, no es suficiente para satisfacer las exigencias del artículo 2 de la Convención en el presente caso. En primer lugar, porque, conforme a lo señalado en los párrafos anteriores, el artículo 2 impone una obligación legislativa de suprimir toda norma violatoria a la Convención y, en segundo lugar, porque el criterio de las cortes internas puede cambiar, decidiéndose aplicar nuevamente una disposición que para el ordenamiento interno permanece vigente(17).

Asimismo, en el caso "Mendoza y otros vs. Argentina", se estableció que "(...) cuando un Estado es parte de un tratado internacional como la Convención Americana sobre Derechos Humanos, dicho tratado obliga a todos sus órganos, incluidos los poderes judicial y ejecutivo, cuyos miembros deben velar por que los efectos de las disposiciones de dichos tratados no se vean mermados por la aplicación de normas o interpretaciones contrarias a su objeto y fin." Esto implica que todos los jueces y órganos vinculados a la administración de justicia en todos los niveles están en la obligación de ejercer ex officio un "control de convencionalidad" entre las normas internas y los tratados de derechos humanos de los cuales es Parte el Estado en el marco de sus respectivas competencias y de las regulaciones procesales correspondientes (18).

Según lo hemos reseñado precedentemente, la Corte IDH ha puesto de relieve la importancia de la realización del control de convencionalidad en el ámbito

(15) Caso Almonacid Arellano y otros $v$ s. Chile. Excepciones Preliminares, Fondo, Reparaciones y Costas. Sentencia de 26 de septiembre de 2006.

(16) Caso Mendoza y otros vs. Argentina. Excepciones Preliminares, Fondo y Reparaciones. Sentencia de 14 de mayo de 2013.

(17) El destacado es propio de los autores.

(18) En esta tarea, los jueces y órganos vinculados a la administración de justicia, como el ministerio público, deben tener en cuenta no solamente la Convención Americana y demás instrumentos interamericanos, sino también la interpretación que de estos ha hecho la Corte Interamericana. 
interno para evitar que los Estados incurran en responsabilidad internacional(19), considerando que ellos son los primeros llamados a cumplir con la labor de protección de los derechos humanos. En este sentido, la Corte IDH ha destacado la subsidiariedad del sistema internacional (en lo contencioso) y ha dado cuenta de la progresiva incorporación del control por parte de la jurisprudencia constitucional comparada. Todo ello significa que - en la práctica - se ha instaurado un control dinámico y complementario de las obligaciones convencionales de los Estados de respetar y garantizar derechos humanos, conjuntamente entre las autoridades internas (primariamente obligadas) y las instancias internacionales (en forma complementaria), de modo que los criterios de decisión puedan ser conformados y adecuados entre sí(20).

A pesar de estar claro tanto su concepto como su desarrollo evolutivo en cuanto a quienes deben aplicarlo, nuestra investigación Lomas CyT (2021)(21) pone de manifiesto la existencia de un gran desconocimiento de la herramienta (control de convencionalidad) en cuanto a su contenido, aplicación y encargados de aplicarla en Argentina en todos sus niveles territoriales atento su circunstancia de Estado Federal.

En efecto, el equipo de investigación realizó encuestas con los sujetos obligados al ejercer el control de convencionalidad (22). Es decir, se encuestaron funcionarios públicos de los tres poderes del Estado tanto en el orden federal, provincial

(19) Véanse los trabajos de Marcelo Neves sobre Transconstitucionalismo, de Eugenio Zaffaroni sobre internacionalización del derecho penal y de Weinberg de Roca sobre jurisdicción constitucional y jurisdicción internacional recogidos en la obra compilada por Capaldo, Steckmann y Clérico sobre internacionalización del derecho constitucional y constitucionalización del derecho internacional (Capaldo et al., 2012).

(20) La Corte IDH no puede realizar de manera exclusiva el control de convencionalidad porque el alcance de su competencia contenciosa no cubre más que una exigua proporción de los diferentes casos en los que día a día en nuestro hemisferio diferentes autoridades públicas se enfrentan a normas internas que violan los derechos humanos reconocidos en las constituciones o en el derecho internacional de los derechos humanos. Por ello el estándar de control de convencionalidad hace que las autoridades internas tengan la obligación de garantizar que el objeto y fin de los tratados se cumpla, enviando además con la adopción de este estándar el mensaje de que cualquier materia judicial o de otra índole puede estar relacionada con el ejercicio de los derechos humanos.

(21) El Control de Convencionalidad en la Argentina y su relación con el principio internacional de progresividad de los Derechos Humanos - Análisis del desarrollo del control de convencionalidad local e internacional - Expediente 260.719/19 Código LOMASCYT IV FD 77. Dirigido por los Dres. Ricardo German Rincón y Lautaro Ezequiel Pittier.

(22) En este punto téngase presente que para los autores la obligación de contrastar la actividad de los funcionarios con las directrices que emanan de la Convención Americana de Derechos Humanos es una obligación que pesa sobre TODOS los poderes del estado y no puede ser solamente endilgada la responsabilidad a los funcionarios judiciales. Del mismo modo sostenemos que todos los niveles territoriales del estado se encuentran obligados a cumplir con las normas convencionales. 
EDUCACIÓN POR Y PARA LOS DERECHOS HUMANOS: EL CASO DEL CONTROL DE CONVENCIONALIDAD - LAUTARo EZEQUiel PitTIER y RiCARDo GERMán RinCón (PP. 367-384)

como municipal. Además, realizó un relevamiento de la jurisprudencia nacional y provincial en donde se aplicó el control de convencionalidad.

Es dable señalar que, a pesar de que los funcionarios realizaron la encuesta de forma anónima, dado que no se revela en ningún caso su identidad, se detectó cierta resistencia a realizarla en los tres poderes fundamentalmente en la provincia de Buenos Aires y en la Ciudad Autónoma. Los funcionarios que respondieron a la encuesta desde la base territorial del municipio bonaerense o en otras provincias (San Luis, Chaco y Tucumán entre otras) mostraron una mayor apertura y predisposición solicitando luego ser informados sobre el resultado de la investigación.

El trabajo se desarrolló en contexto de pandemia por SARS-COVID-19 y las encuestas se realizaron en forma electrónica, utilizando email, WhatsApp y hasta redes sociales, y se realizaron entre el 27 de agosto de 2020 y el 18 de septiembre de 2020. El mecanismo seleccionado originariamente iba a contemplar la combinación de encuestas digitales y presenciales pero el ASPO (aislamiento social preventivo y obligatorio) dispuesto, derivado de la pandemia del COVID-19 definió que solo íbamos a utilizar este instrumento (23).

En efecto, el 11 de marzo de 2020, la Organización Mundial de la Salud declaró al brote del nuevo coronavirus (COVID-19) como una pandemia y, a raíz de ello, nuestro país amplió la Emergencia Sanitaria y le brindó al Ministerio de Salud la facultad para tomar todas las medidas necesarias a fin de minimizar el contagio y fortalecer la capacidad de respuesta del sistema sanitario.

En este marco, atendiendo a las recomendaciones de los organismos internacionales especializados y de los expertos locales, y a la luz de la experiencia de otros países, se determinó que la mejor forma que tenemos para enfrentar la propagación del virus y así cuidar de la salud de todos y todas es el aislamiento. Por ello, el Poder Ejecutivo Nacional dictó el Decreto de Necesidad de Urgencia № 297/2020 mediante el cual determinó la medida de aislamiento social, preventivo y obligatorio.

En idéntico sentido, las Resoluciones No 103/20 y 104/20 del Ministerio de Educación de la Nación, la Resolución nro. 12/20 de la Secretaría de Políticas

(23) El aislamiento social, preventivo y obligatorio es una medida excepcional que el Gobierno nacional adopta en un contexto crítico. Con el fin de proteger la salud pública frente a la propagación del nuevo coronavirus, se dispuso que todas las personas que habitan, o se encuentren temporalmente, en las jurisdicciones donde rige esta normativa deberán permanecer en sus domicilios habituales, solo pudiendo realizar desplazamientos mínimos e indispensables para aprovisionarse de artículos de limpieza, medicamentos y alimentos. Considerando que la situación epidemiológica no es homogénea dentro del territorio nacional, la administración del aislamiento adoptará una modalidad que contemple la realidad de las diversas jurisdicciones del país. 
Universitarias, la Resolución № 59/2020 y concordantes $77 / 20$, de fecha 04 de mayo, del Señor Rector de la Universidad Nacional de Lomas de Zamora, Dr. Diego Alejandro Molea y las Resoluciones de esta Unidad Académica A/No0353/20, $\mathrm{A} / \mathrm{N}^{\circ} 0357 / 20, \mathrm{~A} / \mathrm{N}^{\circ} 0360 / 20$ y A/No0368/20 que básicamente determinaron la suspensión de la actividad académica presencial y la continuación del calendario académico a través de la virtualidad por medios telemáticos.

En razón de ello, tal y como se adelantó, una gran parte de este trabajo debió realizarse en forma virtual, entre ellos las encuestas y las entrevistas. La tarea se realizó contactando a los encuestados previamente y en proporciones equitativas en cuanto al desempeño de los funcionarios públicos en relación con el sector del poder al que pertenecen. También se consideró el ámbito de pertenencia territorial de los funcionarios. La encuesta no se aplicó al ámbito académico, es decir, no se encuestó el grado de conocimiento que sobre el tema tienen los docentes de las carreras de abogacía de las facultades de derecho. Esta arista del tema podrá ser abordada como problema en otra convocatoria o en una ampliación de la presente investigación atento que de las respuestas recibidas se deriva la posibilidad de complementar la misma explorando estas y otras cuestiones.

\section{Gráfico 1. Pertenencia de los encuestados}

\section{Por favor, indique dónde desempeña su función profesional}

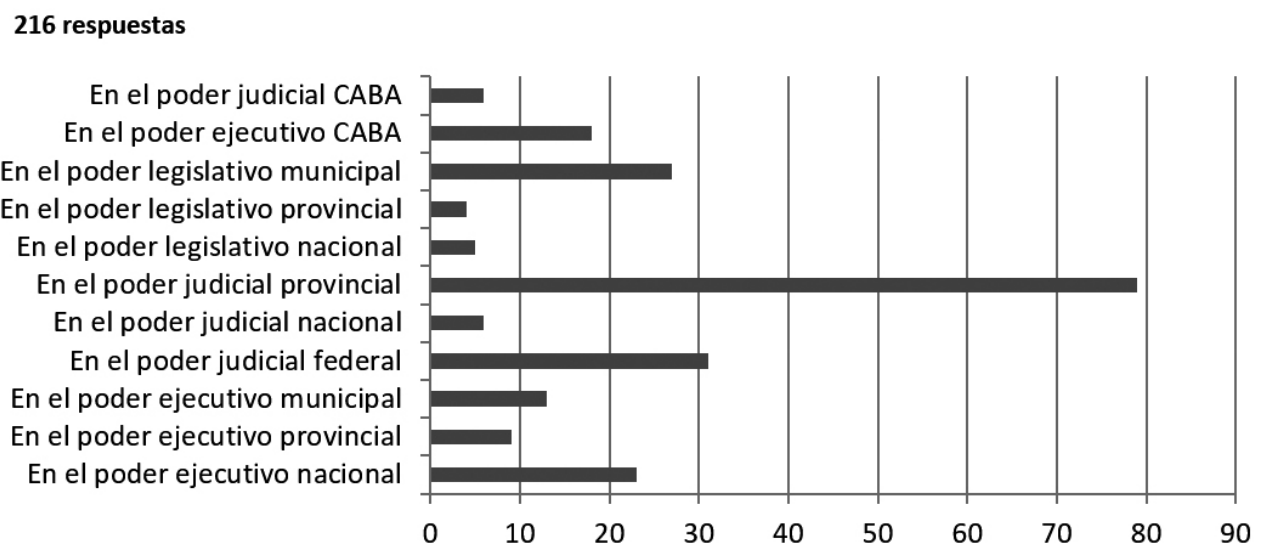

Fuente: elaboración propia.

En primer lugar, puede adelantarse que los funcionarios del Poder Judicial participaron más activamente en la encuesta que funcionarios de los otros poderes. Como podrá apreciarse en los datos obtenidos que se observan a continuación: 
En tal sentido, participaron 74 funcionarios judiciales y del ministerio público entre jueces, defensores oficiales y fiscales. Entre los participantes encontramos integrantes de Cámaras de Apelaciones y Jueces de Superior Tribunal de Justicia Provincial, 28 jueces federales, 22 funcionarios del Poder Ejecutivo Nacional y funcionarios provinciales o de la Ciudad Autónoma de Buenos Aires. Los funcionarios del poder legislativo fueron los más remisos a responder la encuesta que se les envió a sus correos oficiales. Cabe aclarar que las encuestas iban precedidas de un texto explicativo que narraba los objetivos de la investigación y la adopción de la encuesta como mecanismo de recolección de datos, poniéndose a disposición de los funcionarios el marco teórico y la fundamentación del proyecto.

Gráfico 2. Conocimiento sobre el control de convencionalidad de acuerdo con las respuestas de los encuestados

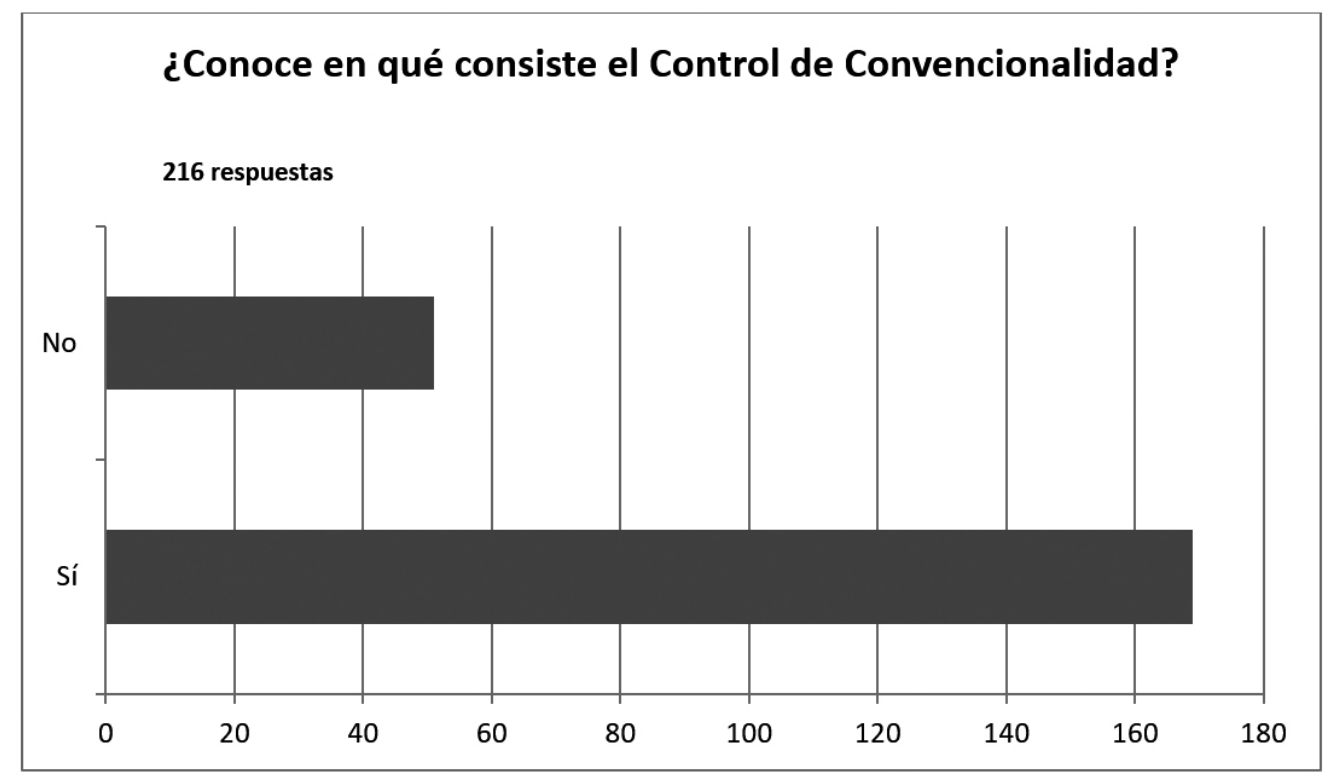

Fuente: elaboración propia.

Consultados acerca del conocimiento del Control de Convencionalidad, el $77.7 \%$ manifestó conocer en que consiste.

Ahora bien, lo que sorprende a los investigadores es que el $81,5 \%$ de los encuestados manifestó que en la dependencia del Estado en la que se desempeñan no recibieron capacitación alguna acerca del control de convencionalidad. Esto podría explicar por qué más del $62 \%$ de las autoridades públicas de los tres poderes del Estado contestaron en forma errónea el sujeto obligado a ejercer dicho control. La frase "la enfermedad del ignorante es ignorar su propia ignorancia" en este contexto se aplica a la perfección. 
En este punto, debe tenerse presente que la asignatura derechos humanos no figuraba como tal en los planes de estudio de la carrera de abogacía de las universidades argentinas. Fue la Universidad Nacional de Lomas de Zamora la primera en incluirla en su currículum y recientemente el proceso de acreditación de las carreras de abogacía llevó a la totalidad de las universidades (tanto de gestión estatal como privada) a incorporar el tema (24). Es posible, por lo tanto, que nos encontremos ante un déficit de formación previa en algunos casos y ante una falta de actualización por la otra por parte de los hombres y mujeres encargados de llevar adelante el control de convencionalidad(25).

\section{Gráfico 3. Autoridad encargada de realizar el control de convencionalidad}

\section{Indique quiénes dentro de este listado deben ejercer el denominado control de convencionalidad}

216 respuestas

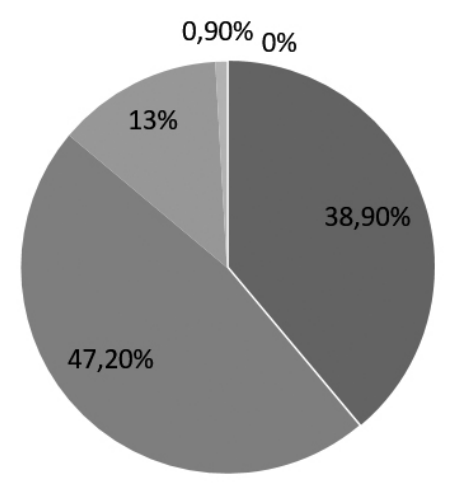

- Toda autoridad pública

- Cualquier juez

- Los jueces de la Suprema Corte de Justicia

Los fiscales

Los auxiliares de justicia

Fuente: elaboración propia.

Asimismo, se consultó a los encuestados si en el ejercicio de la función habían aplicado el control de convencionalidad en al menos una ocasión. A esta pregunta

(24) Las universidades, en algunos casos, han incluido el tema de los derechos humanos en materias específicas mientras que en otras han "repartido" los contenidos en diferentes asignaturas. Este análisis es materia de una futura investigación de los autores.

(25) No es el propósito de este trabajo entrar en la cuestión de la inamovilidad de los magistrados, pero ciertamente se aprecia que esta disposición constitucional tomada de un texto del siglo XVIII como fue la constitución de los Estados Unidos no parece estar muy de acuerdo con el grado de actualización del conocimiento que se vive hoy en día. 
los encuestados respondieron que no en un $68 \%$, cifra que a nuestro juicio resulta bastante desalentadora por cuanto implica que la herramienta no parece estar incorporada al repertorio al que echan mano a cotidiano cuando resolver un problema sometido a su jurisdicción. No obstante, a pesar de que el panorama resulta desalentador, también es entendible, ya que está reflejando que las personas que ocupan los cargos públicos no conocen la posibilidad ni obligación de la aplicación del control de convencionalidad(26).

Finalmente, al analizar el gráfico 3 queda también a la vista el desconocimiento del pretendido carácter difuso, oficioso y transversal(27) del instituto. En efecto, el $47,9 \%$ de los encuestados contestó que el control de convencionalidad puede ser ejercido por cualquier juez, un 13,3\% indicaron que solo los Jueces de la Corte Suprema de Justicia, un $37,9 \%$ que toda autoridad pública y tan solo el $0,9 \%$ que los fiscales deben ejercerlo. Lo expuesto demuestra un alto grado de ignorancia - 62,1\% - acerca de una herramienta cuyo uso adecuado evitaría el incumplimiento de obligaciones internacionales y la posterior sanción a los estados. Esto demuestra, por otra parte, la falta de capacitación de los agentes con mayor responsabilidad institucional para concretar la vigencia de los derechos humanos.

\section{A modo de conclusión}

Como puede inferirse del trabajo realizado, el control de convencionalidad es un instrumento desarrollado para que los derechos humanos que el estado dice sostener al haberse adherido a la CADH se encarnen en la realidad concreta. Para ello resulta necesario que los operadores encargados de su aplicación conozcan de la existencia de la herramienta y de sus posibilidades de empleo en defensa de los derechos de las personas.

No obstante, nos encontramos con que existe un importante desconocimiento en Argentina de la obligación internacional de ejercer el citado control de convencionalidad por parte de los actores del sistema, quienes devienen, precisamente, en los sujetos activos obligados a ejercer dicho control. La afirmación precedente se basa en la comprobación de que más del $60 \%$ de los encuestados respondieron equivocadamente la pregunta sobre la autoridad encargada de realizar el control. Resulta, por otro lado, especialmente notable verificar en el poder judicial la escasa aplicación de este control en las sentencias judiciales que fueron analizadas por este equipo.

(26) Desconociendo a su vez el concepto, funcionamiento y marco normativo.

(27) Difuso porque puede ser ejercido por cualquier autoridad independientemente de su grado o fuero; oficioso porque no necesita ser solicitado por las partes y transversal porque resulta aplicable en cualquier rama del poder o nivel territorial. 
Asimismo, resulta preocupante constatar la falta de capacitación de las autoridades públicas de los cuatro poderes del estado en esta materia. Ello acarrea como consecuencia que no se tengan en cuenta los estándares internacionales al momento de confeccionar un acto administrativo, un decreto, una ordenanza municipal, una sentencia o resolver un expediente administrativo.

Si bien se aprecia que en las sentencias se citan normas internacionales, fallos de la Corte Interamericana y opiniones consultivas no se indica la convencionalidad o falta de convencionalidad de una norma o de un acto del derecho interno. Esto nos lleva a preguntarnos si no podríamos estar asistiendo a un control de convencionalidad ejecutado deficientemente, ya sea por falta de conocimiento o de capacitación lo cual redunda en una capitis deminutio, al menos simbólica, del funcionario en términos de su idoneidad.

Por otro lado, puede decirse que existe poca oferta específica en Argentina (a nivel tanto del estado nacional como de los estados provinciales y municipales) de capacitación en materia de estándares internacionales de derechos humanos y control de convencionalidad. Esta afirmación no desconoce que existen diplomaturas o posgrados (especializaciones, maestrías y doctorados) que estudian la cuestión y apunta en dirección a la falta de oferta de cursos específicos que trabajen la aplicación práctica de los criterios, doctrinas e interpretaciones de la Corte Interamericana de Derechos Humanos para las/os abogadas/os del estado en cualquiera de sus niveles territoriales o poderes. Esta afirmación resulta constatable verificando la agenda pública de capacitaciones de los diferentes poderes del estado en sus distintas manifestaciones territoriales.

Por otro lado, vemos que muy recientemente (2017/2018) se ha incorporado la enseñanza de los derechos humanos en los planes de estudio de la totalidad de las universidades del país. Ello tendrá a futuro un decisivo impacto en la materia por cuanto la/os graduada/os de la carrera de abogacía saldrán formados en estas competencias y podrán transferirlas a sus prácticas.

Así las cosas y recurriendo a la simbología, encontramos que el remedio analizado no ha pasado de la estantería al cuerpo del paciente, por lo que muy difícilmente pueda curar la patología para la cual se diseñó. Entendemos que solo una firme apuesta por lo educación por y para los derechos humanos, sostenida en el tiempo independientemente del color político de los gobiernos de turno, podrá hacer que se vuelva realidad la aspiración a una verdadera vigencia del estado de derecho. 


\section{Bibliografía}

Albanese, S. (coord.) (2008). El control de convencionalidad. Buenos Aires: Ediar.

Albanese, S. (1997). Derechos humanos. Buenos Aires: Belgrano.

Basílico, R. A. (2016). Manual básico de buenas prácticas para la atención de víctimas de trata de personas y violencia de género CABA. Buenos Aires: Konrad Adenauer Stiftung.

Bidart Campos, G. J. (2006). Teoría General de los Derechos Humanos, $1^{\text {a }}$ reimpresión. Buenos Aires: Astrea.

Buenader, E. (2018). La doctrina del margen de apreciación nacional y la obligatoriedad de los fallos de la Corte Interamericana de Derechos Humanos. El Derecho, marzo 2018 (pp. 279-489).

Bielli, G.; Pittier, L. E. (2018). Discapacidad y accesibilidad en la era del expediente digital el caso de los abogados ciegos o con baja visión. Buenos Aires: La Ley.

Capaldo, G.; Steckmann, J. y Clérico, L. (dir.) (2012). Internacionalización del derecho constitucional, constitucionalización del derecho internacional. Buenos Aires: EUDEBA.

Carnota, W. (2005). Derecho Federal, sus implicancias prácticas. Buenos Aires: Grün.

Cossio, C. (2008). La plenitud del orden jurídico y la interpretación judicial de la ley. San Justo: Struhart \& Cía.

Dalla Via, A. R. (2009). Manual de Derecho Constitucional. Buenos Aires: Abeledo Perrot.

Ekmedjian, M. A. (2009). Manual de la Constitución Argentina, 6a ed. Buenos Aires: Lexis Nexis Argentina.

Fayt, C. (2007). El efectivo cumplimiento de las decisiones de la Corte Suprema de Justicia de la Nación. Buenos Aires: La Ley.

Gargarella, R. (2014). La sala de máquinas de la constitución. Dos siglos de constitucionalismo en América Latina (1810-2010). Buenos Aires: Katz.

Gelli, M. A. (2008). Constitución Nacional comentada. $4^{\mathrm{a}}$ ed. Buenos Aires: La Ley. 
Gialdino, R. E. (2013). Derecho Internacional de los Derechos Humanos: principios, fuentes, interpretación y obligaciones. Buenos Aires: Abeledo Perrot.

Gozaíni, O. A. (2018). Estudios de derecho procesal constitucional: por un código procesal constitucional para Latinoamérica. Buenos Aires: Jusbaires.

Linares, J. F. (2015). Razonabilidad de las leyes. El "debido proceso" como garantía constitucional innominada. $2^{\text {a }}$ ed. Buenos Aires: Astrea.

Loianno, A. y otros (2020). Lecciones de Derechos Humanos. Buenos Aires: ERREIUS.

Manili, P. L. (2016). Constitucionalismo Social. Buenos Aires: Astrea.

Manili, P. L. (2007). Evolución de la jurisprudencia de la Corte Suprema de Justicia de la Nación 1863-2007. Buenos Aires: Universidad

Midón, M. A. R. (2016). Control de convencionalidad. Buenos Aires: Astrea.

Morello, A. M. (1998). Constitución y proceso. La nueva edad de las garantías jurisdiccionales. La Plata: Librería Editora Platense.

Neuman, E. (1994). El abuso de poder en la Argentina y otros países latinoamericanos. Buenos Aires: Espasahoy.

Nino, C. (1992). Un país al margen de la ley. Buenos Aires: Emecé.

Palacio de Caeiro, S. B. (2011). Constitución Nacional en la Doctrina de la Corte Suprema de Justicia de la Nación. Buenos Aires: La Ley.

Pastor, D. R. (dir.) y Guzmán, N. (coord.) (2013). El sistema penal en las sentencias recientes de los órganos interamericanos de protección de los derechos humanos. Buenos Aires: Ad-Hoc.

Pellet Lastra, A. (2001). Historia política de la Corte (1930-1990). Buenos Aires: Ad Hoc.

Pittier, L. E. (2018). La Culpa la tienen los Derechos Humanos. Revista Internacional de Derechos Humanos, № 68, diciembre de 2018. ISSN 1015-5074. San José: Instituto de Derechos Humanos.

Pittier, L. y Rincón R. G. (2019). El Margen de Apreciación Nacional en la lectura de los tratados internacionales: ¿laberinto o techo del derecho internacional de los derechos humanos? Diario de Doctrina y Jurisprudencia, Universidad Católica Argentina. ISSN 1666-8987. Buenos Aires: El Derecho. 
Pittier, L. (2018). El estándar de libertad de expresión y sus nuevos desafíos. Revista Internacional de Derechos Humanos (8) (pp. 111-127). ISSN 250-5210 y eISSN 2422-7188.

Pittier, L. E. (2017). Control de convencionalidad: ¿un cambio de rumbo? Suplemento de Derecho Constitucional. Buenos Aires: Albremática.

Pittier, L. E. (2017). El acceso a la Justicia de las personas con discapacidad o con capacidad restringida. Suplemento de Derecho Civil. Buenos Aires: Albremática.

Pittier, L. E. (2017). Algunas notas sobre el fallo Fontevecchia y D'Amico vs. Argentina por la corte interamericana de derechos humanos. Buenos Aires: Utsupra.

Pittier, L. E. (2019). La Interpretación de la Convención Americana de Derechos Humanos y la Eficacia de las Sentencias de la Corte Interamericana. Diario de Doctrina y Jurisprudencia. Buenos Aires: El Derecho.

Pittier, L. E. (2019). El reconocimiento de la Identidad de Género por parte del Sistema de Salud. Diario La Ley, 18/09/2019. Buenos Aires: La Ley.

Rincón, R. G. (2020). La evolución de los DDHH en la Constitución, Diálogos y tensiones entre la Constitución formal y la Constitución material. En M. Leturia (dir.), Anuario Principales actividades de la Facultad de Derecho y Ciencias Sociales de la Universidad del Este, año 2019. La Plata: Librería Editorial Platense.

Fecha de recepción: 25-05-2021

Fecha de aceptación: 06-09-2021 
